\title{
Self-Evaluation of Masters in Nursing Program: Postgraduates' Networks
}

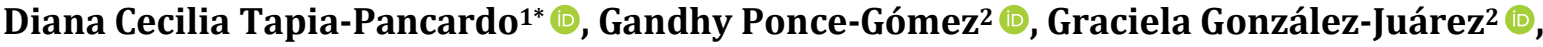 \\ Alejandra Valencia-Cruz ${ }^{3}$ (i), Daniela Cocolotl-González ${ }^{4}$, Rodrigo Montero Díaz ${ }^{5}$
}

\author{
${ }^{1}$ Graduate and Research Division, Biomedicine Unit, Faculty of Higher Studies Iztacala, National Autonomous University of \\ Mexico, Tlalnepantla, Mexico \\ ${ }^{2}$ Masters in Nursing Coordination Program, National School of Nursing and Obstetrics, National Autonomous University of \\ Mexico, Mexico City, Mexico \\ ${ }^{3}$ Faculty of Psychology, National Autonomous University of Mexico, Mexico City, Mexico \\ ${ }^{4}$ National Pedagogical University-Ajusco, Mexico City, Mexico \\ ${ }^{5}$ National School of Nursing and Obstetrics, National Autonomous University of Mexico, Mexico City, Mexico \\ Email:*dianacecitapia@hotmail.com
}

How to cite this paper: Tapia-Pancardo, D.C., Ponce-Gómez, G., González-Juárez, G., Valencia-Cruz, A., Cocolotl-González, D. and Díaz, R.M. (2020) Self-Evaluation of Masters in Nursing Program: Postgraduates' Networks. Open Journal of Nursing, 10, 1056-1067.

https://doi.org/10.4236/ojn.2020.1011075

Received: October 19, 20200

Accepted: November 21, 2020

Published: November 24, 2020

Copyright $\odot 2020$ by author(s) and Scientific Research Publishing Inc. This work is licensed under the Creative Commons Attribution International License (CC BY 4.0).

http://creativecommons.org/licenses/by/4.0/

\section{(c) (i) Open Access}

\begin{abstract}
Background: To ensure quality and relevance of Postgraduate Programs are a commitment of the National Quality Postgraduate Programs (PNPC), and those from UNAM. Then, the self-evaluation of the Masters in Nursing Program (PME) is necessary for it to be part of the PNPC. This study focuses on self-evaluation of implementation mechanisms to assure effective communication and collaboration with and among graduated alumni. Methods: The research was qualitative, exploratory and descriptive. An informed consent was signed by four informants, graduated from the seventeenth generation of PME. Data collection from a focal group and descriptive data analysis by atlas.ti from guidance questions that were contrasted with the scale value from PME curriculum. Results: Four categories emerged from PME graduated alumni: Category I, Professional academic performance, Category II, International activities attendance, Category III, Academic networks, and Category IV, Higher satisfaction of international activities. Conclusions: It is concluded that self-evaluation shows a graduate's vision of conditions and networks where PME develops. Masters in Nursing Program fulfills graduates expectancy to create networks, which will contribute to knowledge and recognition of professional practice, as well as on the area' opportunities opening for better contributions.
\end{abstract}

\section{Keywords}

Master in Nursing Program, Self-Evaluation, Graduates Networks 


\section{Introduction}

To recognize and assure the quality and appropriateness of postgraduate programs are the guiding principles of the National Quality Postgraduate Programs (PNPC), which are based on the National Council of Science and Technology (CONACyT) framework [1]. PNPC model highlights both attributes in two directions, i.e., Research offered as specialty, masters and doctoral degrees in all areas of knowledge, and Professional offered as specialty, masters and doctoral degrees with the goal to collaborate with sectors of society; PNPC role comprises four levels in each Research and Professional orientations. These levels are supported by their International competitiveness, Consolidation, Development and recent creation, explained in Figure 1.

Once the postgraduate program is incorporated into any PNPC role, it should be adjusted to a model of renewal and follow-up evaluated through 13 criteria (divided into 3 categories) as well as the improving plan, such that those are ineludible requirements determinant for a program of good quality.

The way to be incorporated into PNPC involves a careful fulfillment of each criterion, where the program that seeks its accreditation or permanence is self-evaluated by its institution as a necessary condition. This requires a systematic and collegiate process by the peers to reflect upon strengths and potential areas in the postgraduate programs. With this goal, and as part of a larger project, i.e., "Self-evaluation of Masters in Nursing (PME): criteria and indicators of PNPC for programs of international competitiveness", with registration number 123 of the Research Committee from Investigation and Postgraduate Division, National School of Nursing and Obstetrics in 2019 [2]. A multidisciplinary team focused on those established criteria searched for the networks of graduates from PME, with the aim of self-evaluation to implement mechanisms
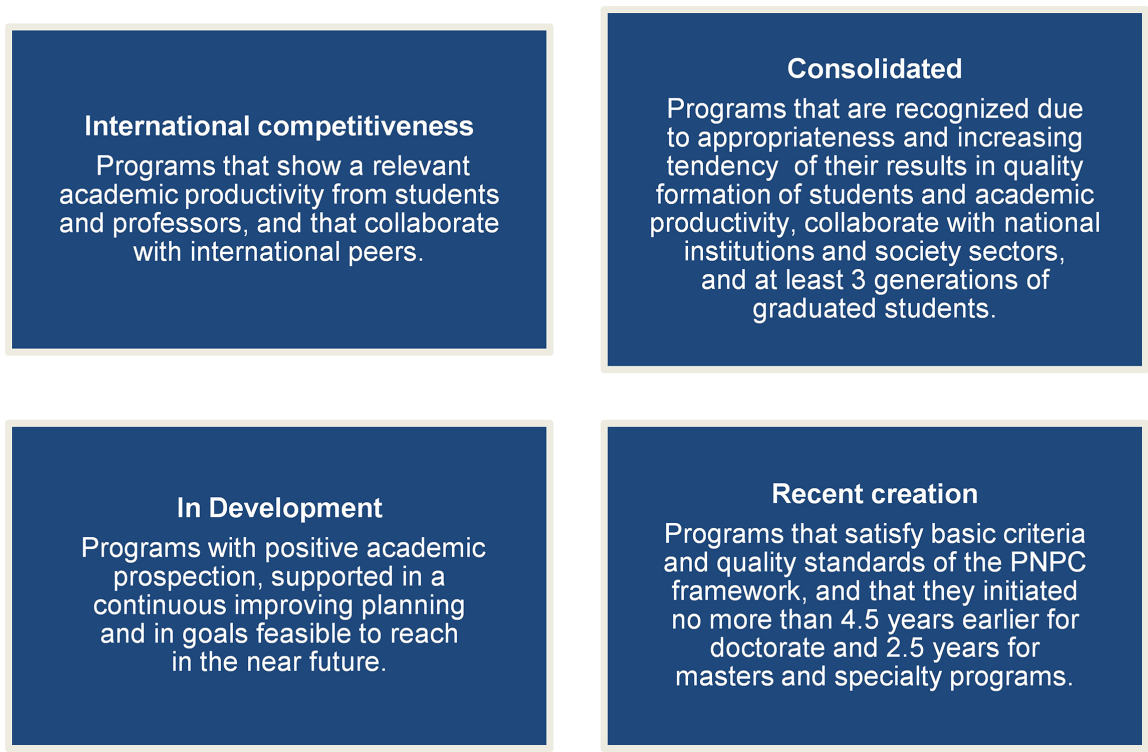

Figure 1. Levels in PNPC role, CONACyT, 2019. Source: Authors' own based on PNPC, CONACyT, 2019. 
to assure effective communication and collaboration with and among graduated alumni, and their feedback for the graduate program, the professional practice, the job placement, and retribution to society. In addition, it provides elements to identify indicators of international competitiveness in PME as requested by the PNPC-CONACyT [3]. So the research question arises: How do graduates perceive the implementation mechanisms to ensure effective communication and collaboration with and among graduates, and their feedback for the graduate program?

\section{Framework}

Educational evaluation in higher education was developed for 3 decades starting with the works of Cronbach (1983), Scriven (1967), Stake (1967), and Stufflebeam (1983) that contributed theoretically and methodologically to the research of evaluation supported in experimentation [4] [5] [6] [7]; even though the current context demands a new paradigm of evaluation seeking to attend social problematic, which need more often of professionals to solve uncertainty and complexity of educational and health phenomena, where self-evaluation is a setting in the construction of learning communities, and recognize the sociopolitical perspective of evaluation [8] [9] [10] [11].

The model published by CONACyT (2019), regarding the renewal and follow-up PNPC process, includes the international good practices for evaluation and accreditation of postgraduate programs such as evaluation by academic peers, who decide on the acceptance or permanence in PNPC [1]. Postgraduate programs must comply with several markers of the PNPC-CONACyT 2019 model [3]; some of them are highlighted in Table 1. In the National Autonomous University of Mexico (UNAM), self-evaluation, as well as institutional evaluation of postgraduate programs, takes place every 5 years, in agreement with the Postgraduate Curriculum Regulation (2019) [3], this means that all programs will be evaluated by the end of 2020; in specific for PME we have to support its quality as a macro-project (ENEO-UNAM, registered with number 123 of Research Committee 2019), which has an ineludible social commitment [2].

During self-evaluation each criterion per category is described, its compliance appraisal according to the program status or in view of its daily functioning. It is important that in each criterion a judgement value is expressly typed to assess its daily reality, compared with criteria and categories stated in the model. The main objective of self-evaluation is to reach a vision about conditions where a postgraduate program develops. It allows identifying strengths and weaknesses to conduct a systematic improving planning and their follow-up.

In order to self-evaluate we need to describe PME history, starting in 2000 the project was approved by the Honorable University Board on October $4^{\text {th }}, 2002$; it is a joint project of three faculties: National School of Nursing and Obstetrics, Faculty of Higher Studies Iztacala and Faculty of Higher Studies Zaragoza, and when the Academic Committee was integrated it incorporated the directors of the Institute of Biomedical Investigations and the Institute of Social Investigations [12]. The goal of this curriculum was to train masters in nursing at a high 
Table 1. Traits of postgraduate programs, PNPC-CONACyT 2019, model.

\begin{tabular}{|c|c|c|}
\hline Criterion & Trait & Example \\
\hline $\begin{array}{l}\text { Students selection } \\
\text { process }\end{array}$ & $\begin{array}{l}\text { Strict, objective and uses norms or procedures. } \\
\text { Admission of the best students warrants the } \\
\text { relevance of the results and programs impact. }\end{array}$ & $\begin{array}{l}\text { Procedures and admission criteria adjust to } \\
\text { programs goals and are public, accessible and } \\
\text { warrant the proper formation of the admitted class. } \\
\text { Students from different institutions and countries } \\
\text { could be enrolled in the program. }\end{array}$ \\
\hline Graduation profile & $\begin{array}{l}\text { The program aims to study in depth a professional } \\
\text { area to attend the potential labor market demand, } \\
\text { as well as the immediate impact on the social sector. }\end{array}$ & $\begin{array}{l}\text { Describe knowledge, attitudes, ethical and } \\
\text { sustainable values that a postgraduate program } \\
\text { student must bear at the end of the training. }\end{array}$ \\
\hline Curriculum & $\begin{array}{l}\text { Postgraduate program shows a well structured } \\
\text { curriculum, oriented to satisfy professional } \\
\text { needs in all society sectors. }\end{array}$ & $\begin{array}{l}\text { Curriculum shows evidence of collaboration with society } \\
\text { sectors that need their professional training, among } \\
\text { them are stays in productive sector, in government, } \\
\text { of services or any other related to the program. }\end{array}$ \\
\hline $\begin{array}{l}\text { Students and teachers } \\
\text { mobility }\end{array}$ & $\begin{array}{l}\text { Students and teachers mobility actions } \\
\text { improve the training process and in the } \\
\text { results to reach consolidated status. }\end{array}$ & $\begin{array}{l}\text { Program shows evidence that students and teachers } \\
\text { participate in mobility actions. There are informs or } \\
\text { proceedings of projects, co-directed thesis (concluded } \\
\text { or in progress), advise, or publications in cooperation } \\
\text { agreements with society sectors. }\end{array}$ \\
\hline $\begin{array}{l}\text { Academic productivity } \\
\text { of the program }\end{array}$ & $\begin{array}{l}\text { Results of applying knowledge and innovation, } \\
\text { and their impact on academic, social, productive } \\
\text { and government sectors. }\end{array}$ & $\begin{array}{l}\text { Measure of productivity results incidence in government, } \\
\text { productive, social, and educational sectors, according } \\
\text { with programs' orientation and level. Networks }\end{array}$ \\
\hline Graduates networks & $\begin{array}{c}\text { Results of implementation mechanisms to effectively } \\
\text { communicate/collaborate with graduates, feedback } \\
\text { on the program, professional practice, employability } \\
\text { and social retribution. }\end{array}$ & $\begin{array}{l}\text { Graduates contribution to knowledge and } \\
\text { professional practice, and their } \\
\text { recognition by society. }\end{array}$ \\
\hline
\end{tabular}

level, with a solid discipline basis that contributes to solve national health problems according to their competitiveness, able to innovate practices for care, nursing education, and administration through disciplinary and multidisciplinary research. The curriculum involved two areas: Basic area and Fields of knowledge area; the Basic area has two curriculum axis: Theory of Care and Research in Nursing, both taken in semesters 1 and 2, and for semester 3 students were involved either in Nursing Education or Administration of Nursing Care fields of knowledge, which continued for semester 4 [12].

Later, in 2014 an Academic Committee was integrated by professors of the three faculties of the program with the duty of revising the PME, and in 2015 this Committee presented a suitability and modification project to, and approved by, the Postgraduate Curriculum Board in June 2017, and then by the Academic Board of Biological, Chemical and Health Sciences Area in August 2017, since it responded to the strategic programs of the University Rector (plan 2015-2019) [13]. Suitability and modification of PME focused in nursing development in the academic and labor settings, in health and education programs that need attention, in the needs of graduate training in nursing for the diverse scenarios of professional practice, to the national and international guidelines in 
development, health, education, science and technology, as well as the tendency in graduate studies in nursing, both nationally and internationally showing the lead to curriculum proposals in theoretical and conceptual frameworks that explain, evaluate, and contextualize nursing theory on care as the study objective of the discipline, in addition to social, humanities and health sciences [14].

PME proposal (2015-2017) [14] focused on three elements: 1) plan of wider and open fields of knowledge for individual, family, and groups care approached from this curriculum proposal as well as its coincidence with UNAM's postgraduate educational offering; 2) fulfilling curriculum flexibility adding elective academic activities and selected topics, as well as promoting students' mobility to other postgraduate programs from UNAM and outside; 3) graduation in time was promoted by reducing academic load during the first three semesters of the program, and by incorporating academic activities to graduate in the fourth semester and by including several graduation options. It is expected that these elements improve terminal efficiency and graduation rate, but also strengthen academic quality according to the advancements of science, technology and nursing.

This modification involved also the theoretical update, adjusting the pedagogical model and the objective of the program, the graduate profile development, modification of admission requirements, modification and update of contents and academic activities, standard and complementary bibliography, and suitability and modification of operational guidelines. With this background in the self-evaluation of PME's graduate networks, we focused on the PNPC model established trait that highlights the results of implementation mechanisms for effective communication and collaboration with graduates, the feedback of the postgraduate program, the professional practice, as well as employability and retribution to society.

During self-evaluation, it is aimed to identify the graduates' perception related to international activities promoted by PME, and the impact in their current professional activities, as well as to share elements to identify indicators of the international competitiveness level of the PME, as required by the PNPC-CONACyT, 2019 [1] [3] [15].

\section{Method}

\subsection{Research Type and Method}

Qualitative research, exploratory and descriptive. The method allows the exploration and description of the phenomenon from the perspective of the participants, it proposed participants to share their experiences, opinions, values, behaviors, emotions, feelings, under their experiences in the PME [16].

\subsection{Informers}

PME graduates coming from the different faculties. Inclusion criteria: Graduates of the PME representing the three University entities where the postgraduate 
degree is taught, the National School of Nursing and Obstetrics, the Iztacala Faculty of Higher Studies and the Zaragoza Faculty of Higher Studies, both sexes.

\subsection{Procedure and Data Collection}

A focal group was formed with four graduates ( $75 \%$ female and $25 \%$ male), from class $17^{\text {th }}$ of PME, they represented the three faculties of the program, with one moderator in charge to ask questions and lead discussion; she requested authorization to record the focal group, started a dynamic for the participants to be comfortable and free to speak and comment in 2 hour session, to identify the perception level of graduates regarding international activities promoted by PME, and the impact in their current professional activities and contribute elements to identify indicators of the international competitiveness level of PME, as required by PNPC-CONACYT, 2019 [1] [3]. The study was conducted during May, 2019.

\subsection{Source of Information}

Curriculum, follow-up matrix of the curriculum designed by the institution, instruments for curriculum evaluation, functions of the curriculum follow-up, and evaluation board. A previous revision of documented information and supporting evidence for each evaluation criterion to analyze was done, to support that guide questions for the focal group were reasoned with precise information, brief and true about PME [3] [13] [14] [15]. Dialogues were voice recorded and transcribed.

\subsection{Data Analysis}

Transcription of answers and dialogues from focal group [16] [17], a descriptive analysis by atlas.ti (categorization of answers) from guide questions was done; it was compared with the PME curriculum, and a FODA strengths, opportunities, weaknesses, and threats matrix related to graduates networks analysis was done. In the next work, an improved proposal plan taking in account the 13 criteria of the model is being constructed that will complement the macro-project ENEO-UNAM 2019 [1] [3]. In order to analyze the data obtained in the interviews, the analysis of the qualitative data was carried out, which gave guidelines to preserve the original language of the informants, as well as to inquire about the situation they went through, as well as the perspective they have on their experiences. For data analysis, Miles and Huberman's proposal was developed, carrying out three tasks: acquisition of information, transcription of data and coding, finally reaching conclusions [18].

\subsection{Ethic and Legal Aspects}

Ethic and legal aspects were based in the principles of the Declaration of Helsinki, point 6 "The right to safeguard the integrity of persons must always be respected. All needed precautions must be adopted to respect intimacy of persons, 
reduce to a minimum the impact of the study on their physical, mental and personality". An informed consent letter was signed by each informer according to the Nüremberg code and local law [19] [20].

\section{Results}

Four categories emerged from PME graduated alumni: Category I, Professional academic performance, and subcategories $1.1 \mathrm{Job}$ positioning, admission or promotion, and 1.2 Academic prospective, foray in doctorate, investigation. Category II, International activities attendance, and subcategories 2.1 Positive experiences, 2.2 Promotion of innovation in teaching-learning process, 2.3 Empowering, 2.4 Identity and ethical-professional reinforcement. Category III, Academic networks, and subcategories 3.1 Incursion in the program of researchers in labor area, and 3.2 International and national professional networks, and Category IV, Higher satisfaction of international activities, with subcategories 4.1 Economical support and students' promotion, and 4.2 Advise of international projection for all students (Table 2).

\section{Discussion}

The PME was accredited in 2008 by the PNPC-CONACyT, and from 2013 it has the "Consolidated" status. The adaptations and modifications proposed in 2015 seek to promote the change the status to "International competitiveness" in the PNPC [12].

The PME is responsible to train students at the best level to be graduates able to attend and solve diverse health problems in the country, through a scientific approach and commitment to solve health and education problems via science,

Table 2. Emerged categories.

\begin{tabular}{cc}
\hline Categories & \multicolumn{1}{c}{ Sub-categories } \\
$\begin{array}{c}\text { Category I, } \\
\text { Professional academic } \\
\text { performance }\end{array}$ & 1.1. Job positioning, admission or promotion \\
& 1.2. Academic prospective, foray in doctorate, investigation \\
\hline $\begin{array}{c}\text { Category II, } \\
\text { 2.1. Positive experiences }\end{array}$ & 2.2. Promotion of innovation in teaching-learning process \\
attendance & 2.3. Empowering \\
2.4. Identity and ethical-professional reinforcement \\
$\begin{array}{c}\text { Category III, } \\
\text { Academic networks }\end{array}$ & 3.1. Incursion in the program of researchers in labor Area \\
\hline $\begin{array}{c}\text { Higher satisfaction of } \\
\text { international activities }\end{array}$ & 4.2. Advise of international projection for all students \\
\hline
\end{tabular}

Source: Focal group with four graduates from PME, Mexico City, 2019. 
technology, humanities and ethical issues [13] [14], which is coincident with Category 1. Academic and professional productivity of PME graduates, and subcategories $1.1 \mathrm{Job}$ positioning, admission or promotion, and 1.2 Academic prospective, foray in doctorate, investigation, which emerged from the following speeches:

[ ] I am in charge of nursing coordination, my duties are just administrative and as a teacher I give courses of clinical nursing and attention process in nursing to three groups. In addition, I review dissertations at technical bachelor degree, supervise clinical fields and social service interns and students at the institute. E4

[ ] Currently I am a teacher at UNAM, member of editorial board of a university journal, I am editor-in chief, my duties are administrative and handling of editorial design programs, I am also part of a research seedbed. E2 [ ] PME helped me a lot in my job, since I advise or be part of the academic research group, and because nobody else knows the qualitative approach I had the opportunity to develop this area. E3

[ ] My vision after PME is to incursion in the doctorate focused in anthropology or sociology to be trained, and then develop myself in community nursing with research background and work differently in nursing, not only in clinical aspects. E4

Dr. Enrique Graue Wiechers, UNAM Rector, proposed 17 strategic programs for his Institutional Development Plan (2015-2019) [13], from them 8 have a direct impact on the academic life of PME [14]: 1. Better university education by keeping and increasing quality training from bachelors and university degrees, to develop abstraction abilities, innovation in learning methods, to effectively coordinate different study steps (semesters), merge technology advances to teaching and research to better knowledge acquisition, to promote earlier the interest for investigation. This proposal is coincident with Category II. Contributions of graduates experiences in international activities from PME, and subcategories 2.1 Positive experiences, 2.2 Promotion of innovation in teaching-learning process, 2.3 Empowering, 2.4 Identity and ethical-professional reinforcement, which emerged from the following speeches:

[ ] Simulation practices during the international visits when studying masters program had been very important for my job, because I realized that a lab practice is not just for to give knowledge to the student, but give positive experiences to strength his training for working in hospital. E2 [ ] I traveled with high expectancy and commitment... I think that establish relationships with equal trained peers of other countries, gives us professional maturity. E4

[ ] That experience was essential, to have the chance of present your thesis project abroad to international meetings, with the economical and administrative support to do it, is not part of other programs. E2 
[ ] I brought with me not only the attendance certificate from the meeting, but also the commitment above all for the mental health and adolescents sake, that is what most interest me. E1

[ ] I learned that I can do many things, travel to a foreign country to live experiences with international students is very productive, now $I$ have higher expectancies since it was not only "I came", "I visited", "I did this", no, it was a guideline to want more and more, to professionally and personally grow. $E 4$

Those findings coincide with Graue's proposals (2015-2019) to warrant quality, full validity, and university education consolidation through curricula founding and modifications, regarding society needs and challenges; to impulse students' performance, being close along their processes and careers using strategies as tutoring, scholarships, and diverse teaching modalities to favor their permanence, performance and successful conclusion of their program [13] [14]. The inclusion of learning and knowledge technologies to the process of teaching and learning, to cutting edge research, as well as to culture extension and dissemination that benefits students' integral training and that of society. Another important aspect of Graue's proposal to understand what society requests from the universities is to articulate science, humanities, arts and technology to generate research with interdisciplinary approach to solve complex problems, and the result could be transferred to society [13]; in this regard, PME joins that Plan by suggesting wider knowledge fields and opened, such that individual, family, and groups care could be addressed from this curricular proposal [14], which is coincident with Category III Academic networks from PME graduates, and subcategories 3.1 Incursion in the program of researchers in labor area, and 3.2 International and national professional networks, which emerged from the following speeches:

[ ] I am currently collaborating with a professor that Works for the Army (SEDENA), we have a joint project in the same subject but in the qualitative field, and I help him in other projects; we also contacted a professor from Alicante, Spain, to start a collaboration, and he is in a research stay in Chile to share those research subjects. I also work with the chief of social work to understand this social aspect and apply it to my job. E2

[ ] I am in contact with a Colombian nurse specialized in mental health, trained in Europe, he met me at the poster session about my work, he told me "in my country we use a different model of mental health", we talk about it and since then we keep in touch. E1

[ ] The networking with international health professionals helped me to discover a new panorama, to establish ties with other professionals, diverse graduate programs, and to broad my opinions and thoughts for the health area. E2

PME promotes human holistic development in equal opportunity of rights 
and fundamental freedom, gender equity, interculturality, sustainability, among other values [14], which raises Category IV High satisfaction with international activities from PME, with subcategories 4.1 Economical support and students' promotion, and 4.2 Advise of international projection for all students, which emerged from the following speeches:

[ ] I would not change anything of the PME at the moment, I am very satisfied with it since it promotes academic activities here and in other countries, I was amazed visiting two countries. E1

[ ] I am satisfied with the program, I might add that as a requirement a foreign language because I am working in the corporate field, teaching and research, and we are requested to have certificates of attendance and approval of courses like cardiopulmonary resuscitation, and from associations like the Mexican College of Nursing Graduates (COMLE). E3

[ ] That all professors of PME be willing to open research stays as obligatory and not optional. E2

PME is flexible in its curriculum by adding optional academic activities and selected topics, and to promote students' mobility between UNAM graduate programs and outside, which is in line with Graue's proposal by training professionals with abilities, attitudes and knowledge for successful job insertion in labor field, updated and committed with country's needs [13] [14].

PME is pertaining in suggesting new knowledge fields, such as: nursing theory, health sciences, socio-humanistic sciences, where Nursing education and Administration of Nursing care (2002), initial orientations of the program but is open to diverse approaches, perspectives and dimensions that allow explore life care action, transversality in gender equity, interculturality, bioethics and ethics [12] [13] [14].

\section{Conclusions}

Self-evaluation shows a vision of PME developing conditions from graduates' standpoint. It allowed identifying strengths and weaknesses to conduce a systematic and better planning and its follow-up.

The aim to self-evaluate results of implementation mechanisms to effectively communicate and collaborate with and among graduates, their feedback for the $\mathrm{PME}$, the professional practice, as well as job insertion and the compensation to society was reached, in part, due to a lack of evidence to clarify the compensation to society in this work; however, it allows the follow-up of self-evaluation in this aspect.

The emerged categories contributed to identify indicators to be improved requested by PNPC-CONACyT; it is necessary to promote the academic productivity of students, professors and graduates in international collaborations.

Taken together results allow conclude that PME meets the criterion to have graduates' networks, contributing to knowledge and recognition of professional practice. It also opens opportunity areas for better contribution and compensa- 
tion to society, placing PME in the way to obtain International competitiveness status of PNPC-CONACyT.

\section{Limitations of the Study}

It is difficult to achieve the attendance and participation of the graduates of the master's program due to their working hours, even though several invitations were made. They responded interested in participating, but the times did not coincide.

\section{Authors' Contributions}

The authors collaborated on the research. DCTP advised the design of the protocol and drafted the manuscript, DCTP, AVC, GPG, GJG and DCG processed the manuscript for publication. Authors DCG, RMD and AVC collected and analyzed the data. All the authors read and approved the final manuscript.

\section{Conflict of Interest}

The authors declare no conflicts of interest regarding the publication of this paper.

\section{References}

[1] Consejo Nacional de Ciencia y Tecnología (CONACYT) (2019) Announcement of Admission, Re-Admission and Permanence in On-Campus Learning Postgraduate Programs. Subsecretaría de Educación Superior.

[2] Escuela Nacional de Enfermería y Obstetricia (ENEO-UNAM) (2019) Self-Evaluation on Nursing Masters' Degree: International Criteria and Indexes to Accreditation in PNPC, Register 123 of Research Committee. http://www.eneo.unam.mx/investigacion/ACUERDOS\%20\%202019acen2020.pdf.

[3] Consejo Nacional de Ciencia y Tecnología (CONACyT) (2019) Framework of National Quality Postgraduate Program (PNPC), Version 6.2.

https://www.conacyt.gob.mx/index.php/sni/convocatorias-conacyt/convocatorias-p $\mathrm{npc/marcos-de-referencia-pnpc/19860-fe-de-erratas-marcos-pnpc/file}$

[4] Cronbach, L.J. (1983) Chapter 6: Course Improvement through Evaluation. In: Stufflebeam, D.L., Madaus, G.F. and Kellaghan T., Eds., Evaluation Models. Evaluation in Education and Human Services, Kluwer-Nijhoff Publishing, Boston, 101-115.

[5] Scriven, M. (1967) The Methodology of Evaluation. In: Tyler, R., Gagné, R. and Scriven, M., Eds., Perspectives of Curriculum Evaluation (AERA Monograph Series on Curriculum Evaluation, No. 1), Rand McNally, Chicago, 39-83.

[6] Stake, R.E. (1967) The Countenance of Educational Evaluation. Teachers College Record, 68, 523-540.

[7] Stufflebeam, D.L. and Madaus, G.F. (1983) Chapter 23: The Standards for Evaluation of Educational Programs, Projects, and Materials. In: Stufflebeam, D.L., Madaus, G.F. and Kellaghan, T., Eds., Evaluation Models. Evaluation in Education and Human Services, Kluwer-Nijhoff Publishing, Boston, 395-404.

[8] González-Juárez, G. (2019) Diagnostic Self-Evaluation in Nursing. Revista de Enfermería Universitaria, 16, 74-85. https://doi.org/10.22201/eneo.23958421e.2019.1.589 
[9] San Fabián, M. and Granda, C.A. (2013) Self-Evaluation of Educational Centers. How to Improve from Inside? Síntesis, Madrid, 77-113.

[10] García, C.B. (2010) Theoretical Models and Indicators of Educational Evaluation.

[11] Bonami, M. (2005) Évaluation Internet évaluation Externe: Concurrence ou complémentarité.

[12] Universidad Nacional Autónoma de México (2002) Masters in Nursing Program [Executive Summary]. Escuela Nacional de Enfermería y Obstetricia, Mexico.

[13] Universidad Nacional Autónoma de México (2015) Institutional Development Plan 2015-2019 from Enrique Graue Wiechers, MD. http://www.rector.unam.mx/doctos/PDI-2015-2019.pdf

[14] Universidad Nacional Autónoma de México (2017) Masters in Nursing Curriculum Program: Adaptation and Modification of Masters in Nursing Program.

[15] Universidad Nacional Autónoma de México (2010) 2010 Self-Evaluation Guidelines of Postgraduate Programs. UNAM, México.

[16] Hernández, R., Fernández, C. and Baptista, P. (2018) Investigation Methodology: Quantitative, Qualitative and Mixed Routes. McGraw Hill, México, 524-525.

[17] Berenguera, A., Fernández de Sanmamed, M.J., Pons, M., Pujol, E., Rodríguez, D. and Saura, S. (2014) Listening, Observing and Comprehend: Recovering Narrative in Health Sciences. Contributions of Qualitative Research. Institut Universitari d’Investigació en Atenció Primària Jordi Gol (IDIAP J. Gol), Barcelona.

[18] Informed Consent (2016) National Guidelines to Integer and Functioning of Ethics Committees in Research Comision Nacional de Bioetica. Secretaria de Salud, Mexico, $66 \mathrm{p}$.

[19] Miles, M., Huberman, A., Saldaña, J. and Chapter E. (2014) Ethical Issues in Analysis. In: Miles, M. and Huberman, A., Eds., Qualytative Data Analysis: An Expanded Sourcebook, 3rd Edition, Sage Publications, Thousand Oaks, CA, 107-255.

[20] Noreña, A.L., Alcaraz-Moreno, N., Roja, J.G. and Rebolledo-Malpica, D. (2012) Applicability of the Criteria of Rigor and Ethics in Qualitative Research. Chía, Colombia, 12, 263-274. https://doi.org/10.5294/aqui.2012.12.3.5 